\title{
6G: Envisioning the Key Technologies, Applications and Challenges
}

\author{
Syed Agha Hassnain Mohsan ${ }^{1}$, Alireza Mazinani ${ }^{2}$, Warda Malik ${ }^{3}$, Imran Younas ${ }^{4}$ \\ Nawaf Qasem Hamood Othman ${ }^{5}$, Hussain Amjad ${ }^{6}$, Arfan Mahmood \\ Department of Electrical Engineering, COMSATS University Islamabad (CUI), Islamabad, Pakistan ${ }^{1}$ \\ School of Electronic and Information Engineering, Beihang University, Beijing, China ${ }^{2}$ \\ Department of Electrical Engineering, COMSATS University Islamabad (CUI), Wah, Pakistan ${ }^{3}$ \\ Department of Electronics Engineering, Xi'an Jiaotong University (XJTU), Xi'an, China ${ }^{4}$ \\ Department of Information and Communication Engineering, Xi'an Jiaotong University (XJTU), Xi'an, China ${ }^{5}$ \\ Department of Marine Science and Information Technology, Ocean College, Zhejiang University, Zhoushan, China ${ }^{6}$ \\ Complex Networks and Control Lab, Shanghai Jiao Tong University, Shanghai, China ${ }^{7}$
}

\begin{abstract}
In 2030, 6G is going to bring remarkable revolution in communication technologies as it will enable Internet of Everything. Still many countries are working over 5G and B5G has yet to be developed, while some research groups have already initiated projects on 6G. 6G will provide high and sophisticated QoS e.g. virtual reality and holographic communication. At this stage, it is impossible to speculate every detail of $6 \mathrm{G}$ and which key technologies will mark 6G. The wide applications of ICT, such as IoT, AI, blockchain technology, XR (Extended Reality) and VR (Virtual Reality), has created the emergence of $6 \mathrm{G}$ technology. On the basis of $5 \mathrm{G}$ technique, 6G will put profound impact over ubiquitous connectivity, holographic connectivity, deep connectivity and intelligent connectivity. Notably, research fraternity should focus on challenges and issues of $6 \mathrm{G}$. They need to explore various alternatives to meet desired parameters of $6 \mathrm{G}$. Thus, there are many potential challenges to be envisioned. This review study outlines some future challenges and issues which can hamper deployment of 6G. We subsequently define key potential features of $6 \mathrm{G}$ to provide the state of the art of 6G technology for future research. We have provided a review of extant research on $6 \mathrm{G}$. In this review, technology prospects, challenges, key areas and related issues are briefly discussed. In addition, we have provided technologies breakdown and framework of 6G. We have shed light over future directions, applications and practical considerations of $6 \mathrm{G}$ to help researchers for possible breakthroughs. Our aim is to aggregate the efforts and eliminate the technical uncertainties towards breakthrough innovations for $6 \mathrm{G}$.
\end{abstract}

Keywords-IoT; AI; communication technologies; holographic communication; blockchain

\section{INTRODUCTION}

Although the era of $5 \mathrm{G}$ is not fully developed, the limitations of $5 \mathrm{G}$ have created the demand for $6 \mathrm{G}$ networks. In 2019, communication synergy around the globe drafted first 6G white paper in world's first 6G summit in Finland. After that, many government organizations and research group from prestigious institutes started introducing their $6 \mathrm{G}$ projects. UK government has decided to invest in $6 \mathrm{G}$ technology [1], while Academy of Finland has launched "6 Genesis" project.
What is 6G technology? Some people expect more than just a faster version of $5 \mathrm{G}$. For example, there should be no limitation of coverage to ground level. Instead, it must provide undersea and space coverage. It must enable higher Artificial Intelligence (AI) characteristics. In fact, some researchers consider it as an "AI-empowered" network [2]. It should not merely involve AI but it must integrate AI networking functions and tool. In addition, secrecy, privacy and risk mitigation must be a core component of its architecture [3]. In this review, we have investigated privacy and security challenges along with potential applications of $6 \mathrm{G}$ network. An overview of different dimensions of $6 \mathrm{G}$ networks is shown in Fig. 1.

After commercialization of $5 \mathrm{G}$ network, academia and industrial experts have started thinking about next $6 \mathrm{G}$ network, services and requirements behind it. If we look at standardization methods of $5 \mathrm{G}$ technology, three aspects were investigated as, ultra-reliable and low latency communications (URLLC), massive machine type communications (mMTC) and enhanced mobile broadband (eMBB). Although such scenarios are not fully investigated for $6 \mathrm{G}$ networks, however some pioneering works [4-5] forecast the idea to link everything via unlimited, reliable and instantaneous wireless resources. We have shown an overview of $6 \mathrm{G}$ coverage in Fig. 2.

To bring this revolution to connect everything worldwide, 6G will require extreme communication techniques such as smart living based wireless brain-computer interactions [6], smart working based on seamless holographic projection [7] and smart design considering real-time digital twins [8]. The evolution from $5 \mathrm{G}$ to $6 \mathrm{G}$ is summarized in Table $\mathrm{I}$.

We have provided some performance metrics for $6 \mathrm{G}$ networks below and compared with conventional 5G requirements.

- Mobility: The highest speed to be achieved will be increased from $500 \mathrm{~km} / \mathrm{h}$ to $1000 \mathrm{~km} / \mathrm{h}$.

- Reliability: $99.99 \%$ reliability will be achieved to support unmanned vehicles including AUVs and collaborative robotics. 
- Latency: The communication latency will be decreased by 10 times for end-to-end point of view.

- Throughput: A maximum throughput of $1 \mathrm{~Tb} / \mathrm{s}$ will be needed for $6 \mathrm{G}$ which is 1000 times speedy than $5 \mathrm{G} .100$ times advancement is expected.

- Energy and Spectrum Efficiency: 100 times energy efficiency and 10 times spectrum efficiency will be achieved.

The above described metrics involve disruptive features in 6G networks to use more flexible frame structure, more frequency bands and more spatial dimensions. Many industrial experts and technologies have discussed to meet these requirements. Such as, Space-Air-Ground integrated network [9] have suggested to enhance the spatial degrees of freedom by incorporating airborne, terrestrial and satellite networks, which extend 2D into 3D space for reliable and efficient connectivity [10]. Under-utilized high frequency bands can be explored through Terahertz (THz). Visible light communication (VLC) is a promising candidate for tens of $\mathrm{GHz}$ bandwidth [11] and $1 \mathrm{~Tb} / \mathrm{s}$ throughput. Meanwhile, AI driven communication [12] with intelligent control will be possible.

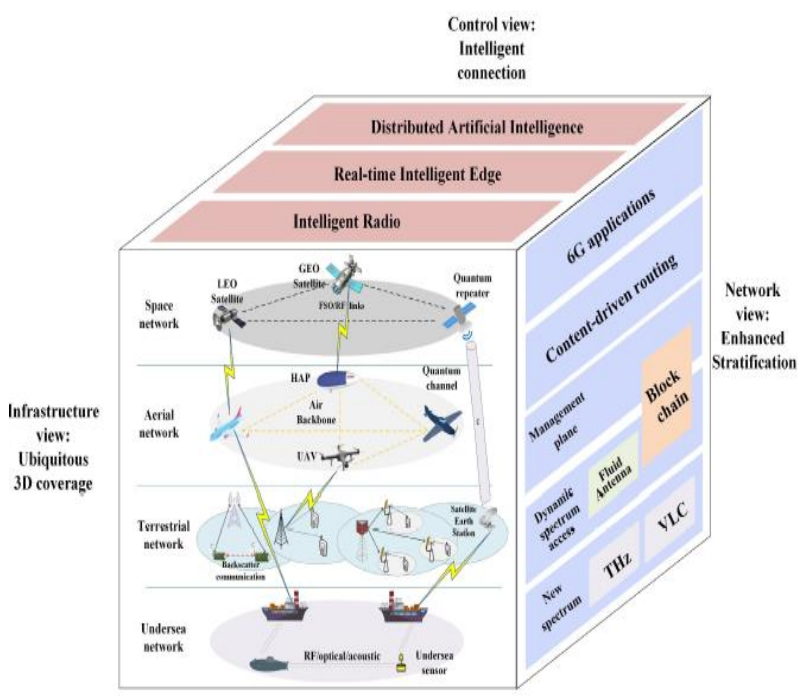

Fig. 1. Different Dimensions of 6G Architecture [17].

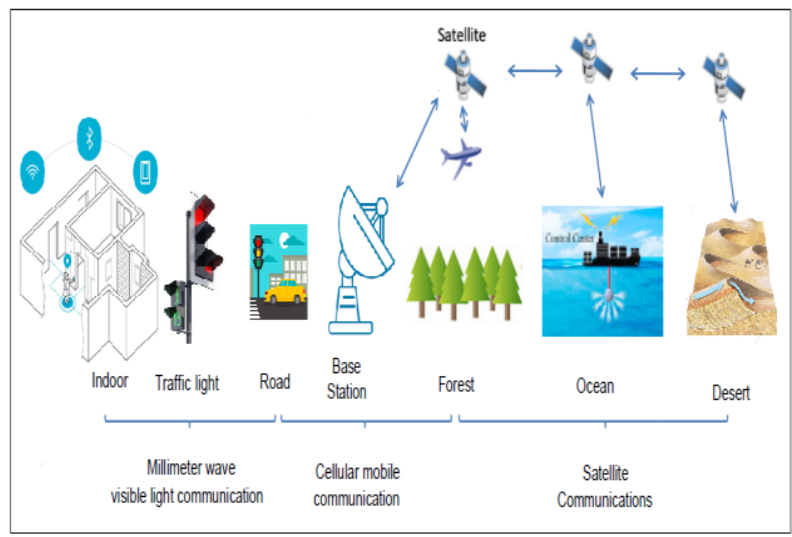

Fig. 2. An Overview 6G Network Coverage.
TABLE I. EVOLUTION FROM 5G TO $6 \mathrm{G}$

\begin{tabular}{|l|l|l|}
\hline Key parameter & $\mathbf{5 G}$ & $\mathbf{6 G}$ \\
\hline Mobility (km/h) & $350-500$ & 1000 \\
\hline $\begin{array}{l}\text { Peak spectral efficiency } \\
\text { (b/s/Hz) }\end{array}$ & 30 & 60 \\
\hline End-to-end latency (ms) & 1 & 0.1 \\
\hline Reliability & $10-5$ & $10-9$ \\
\hline $\begin{array}{l}\text { Connection Density } \\
\text { (device/km2) }\end{array}$ & 106 & 107 \\
\hline $\begin{array}{l}\text { Area traffic capacity } \\
\text { (Mbps/m2) }\end{array}$ & 10 & 1000 \\
\hline $\begin{array}{l}\text { Channel bandwidth } \\
\text { (GHz) }\end{array}$ & 1 & 100 \\
\hline $\begin{array}{l}\text { Spectral efficiency } \\
\text { (b/s/Hz) }\end{array}$ & 0.3 & 3 \\
\hline Energy Efficiency (Tb/J) & $\mathrm{NA}$ & 1 \\
\hline User Data rate (Gbps) & $1 \mathrm{~Gb} / \mathrm{s}$ & $>10 \mathrm{~Gb} / \mathrm{s}$ \\
\hline Peak data rate & $10-20 \mathrm{~Gb} / \mathrm{s}$ & $>100 \mathrm{~Gb} / \mathrm{s}$ \\
\hline Receiver sensitivity & $-120 \mathrm{dBm}$ & $<-130 \mathrm{dBm}$ \\
\hline Position precision & $\mathrm{m}$ & $\mathrm{cm}$ \\
\hline Coverage & $70 \%$ & $>99 \%$ \\
\hline Delay & $\mathrm{ms}$ & $\mathrm{ms}$ \\
\hline & & 100 \\
\hline
\end{tabular}

II. HistoricAl OVERVIEW

\section{A. $1 G$ and $2 G-10$ Times Reduction}

$1 \mathrm{G}$ and $2 \mathrm{G}$ networks provide the basic service of voice calling. Significant contribution has been made from $1 \mathrm{G}$ to $2 \mathrm{G}$ realization, such as China Mobile's annual report revealed 10 times price depletion from 0.1 to 0.01 US dollar/minute [13]. In addition, world's population using these services also increased from $10 \%(1 \mathrm{G})$ to above $50 \%(2 \mathrm{G})$ within 20 years [14].

\section{B. $3 G$ and $4 G-1000$ Times Reduction}

$3 \mathrm{G}$ and $4 \mathrm{G}$ networks provide the key service of data transmission. Technical development from $3 \mathrm{G}$ to $4 \mathrm{G}$ include orthogonal frequency division multiplexing (OFDM) and multiple-input multiple-output (MIMO) and user-sensitive goal of1000 times price reduction. Initial $3 \mathrm{G}$ users are limited to business community to access company resources and emails, while further enhancement occurs only after the deployment of $4 \mathrm{G}$ networks.

\section{5G and 6G-1000 Times Reduction}

An explosive growth of $5 \mathrm{~g}$ and beyond is found to facilitate human-to-machine and machine-to-machine communications. Although the existing $5 \mathrm{G}$ is still based on eMBB with the similar price strategy of $4 \mathrm{G}$ networks. However, it will be more reasonable to charge on the basis of connection rather than data traffic. According to FTTH systems, China is charging 100200 US dollars for each terminal [15]. However, 100 trillion sensors are expected to be manufactured and connect to internet by the end of 2030 to revolutionize 6G. Hence, 1000 times price reduction will be required to develop a sustainable smart society. Table II summarizes different features of $5 \mathrm{G}$ and $6 \mathrm{G}$.

A details comparison of $1 \mathrm{G}$ to $6 \mathrm{G}$ [16] technologies is summarized in Table III. 
TABLE II. COMPARISON BETWEEN 5G AND 6G

\begin{tabular}{|l|l|l|}
\hline Feature & $\mathbf{5 G}$ & $\mathbf{6 G}$ \\
\hline VLC & No & Yes \\
\hline Reliability & Good & Extreme \\
\hline AI & No & Yes \\
\hline Centre & User & Service \\
\hline Capacity & $1 \mathrm{D} / 2 \mathrm{D}$ & $3 \mathrm{D}$ \\
\hline WPT & No & Yes \\
\hline Core & IoT & IoE \\
\hline Privacy & Good & Extreme \\
\hline Real Time & No & Yes \\
\hline
\end{tabular}

TABLE III. COMPARISON OF $1 \mathrm{G}$ TO $6 \mathrm{G}$ TECHNOLOGIES

\begin{tabular}{|c|c|c|c|c|c|c|}
\hline Feature & $1 G$ & $2 G$ & 3G & $4 \mathrm{G}$ & $5 G$ & $6 \mathrm{G}$ \\
\hline $\begin{array}{l}\text { Time } \\
\text { span }\end{array}$ & $\begin{array}{l}1980- \\
1990\end{array}$ & $\begin{array}{l}1990- \\
2000\end{array}$ & $\begin{array}{l}2000- \\
2010 \\
\end{array}$ & $\begin{array}{l}2010- \\
2020\end{array}$ & $\begin{array}{l}2020- \\
2030\end{array}$ & $\begin{array}{l}2030- \\
2040\end{array}$ \\
\hline Highlight & $\begin{array}{l}\text { Mobil } \\
\text { ity }\end{array}$ & $\begin{array}{l}\text { Digitizat } \\
\text { ion }\end{array}$ & $\begin{array}{l}\text { Internet } \\
\text { connecti } \\
\text { vity }\end{array}$ & $\begin{array}{l}\text { Real- } \\
\text { time } \\
\text { applicati } \\
\text { ons }\end{array}$ & $\begin{array}{l}\text { Extre } \\
\text { me } \\
\text { data } \\
\text { rates }\end{array}$ & $\begin{array}{l}\text { Privacy } \\
\text { secrecy } \\
\text { securit } \\
\text { y }\end{array}$ \\
\hline $\begin{array}{l}\text { Core } \\
\text { network }\end{array}$ & PSTN & PSTN & $\begin{array}{l}\text { Packet } \\
\text { N/W }\end{array}$ & Internet & IoT & $\mathrm{IoE}$ \\
\hline Services & Voice & Text & Picture & Video & $\begin{array}{l}3 \mathrm{D} \\
\mathrm{VR} / \mathrm{A} \\
\mathrm{R}\end{array}$ & Tactile \\
\hline $\begin{array}{l}\text { Architect } \\
\text { ure }\end{array}$ & SISO & SISO & SISO & MIMO & $\begin{array}{l}\text { Massi } \\
\text { ve } \\
\text { MIM } \\
\text { O }\end{array}$ & $\begin{array}{l}\text { Intellig } \\
\text { ent } \\
\text { Surface }\end{array}$ \\
\hline $\begin{array}{l}\text { Multiple } \\
\text { xing }\end{array}$ & $\begin{array}{l}\text { FDM } \\
\text { A }\end{array}$ & $\begin{array}{l}\text { FDMA, } \\
\text { TDMA }\end{array}$ & CDMA & OFDMA & $\begin{array}{l}\text { OFD } \\
\text { MA }\end{array}$ & $\begin{array}{l}\text { Smart } \\
\text { OFDM } \\
\text { A plus } \\
\text { IM }\end{array}$ \\
\hline $\begin{array}{l}\text { Maximu } \\
\mathrm{m} \\
\text { Frequenc } \\
\mathrm{y}\end{array}$ & $\begin{array}{l}894 \\
\mathrm{MHz}\end{array}$ & $\begin{array}{l}1900 \\
\mathrm{MHz}\end{array}$ & $\begin{array}{l}2100 \\
\mathrm{MHz}\end{array}$ & $6 \mathrm{GHz}$ & $\begin{array}{l}90 \\
\mathrm{GHz}\end{array}$ & $10 \mathrm{THz}$ \\
\hline $\begin{array}{l}\text { Maximu } \\
\text { m Data } \\
\text { rate }\end{array}$ & $\begin{array}{l}2.4 \\
\mathrm{~kb} / \mathrm{s}\end{array}$ & $144 \mathrm{~kb} / \mathrm{s}$ & $2 \mathrm{Mb} / \mathrm{s}$ & $1 \mathrm{~Gb} / \mathrm{s}$ & $\begin{array}{l}35.46 \\
\mathrm{~Gb} / \mathrm{s}\end{array}$ & $\begin{array}{l}100 \\
\mathrm{~Gb} / \mathrm{s}\end{array}$ \\
\hline
\end{tabular}

\section{Current Research Progresses Towards 6G}

Many research groups have shown the vision of $6 \mathrm{G}$ and research fraternity has started advance research activities and projects [18-20]. There is a growing inclination in research publications in this domain. Recently, Yang Lu et al. [21] filtered extant articles about $6 \mathrm{G}$ as various institutes have been conducting research on several approaches towards 6G. Publishing trend between 2016 and 2020 is depicted in Fig. 3. $\mathrm{X}$-axis shows the number of publications while $\mathrm{Y}$-axis shows specific year. It can be seen that maximum papers were published in IEEE conferences and journals.

E. Basar et al. [22] have discussed MIMO paradigm for $6 \mathrm{G}$. They focused on research activities related to device manufacturing capabilities. S.M. Bohloul et al. [23] have made a good discussion about trends, opportunities and developments in 6G. They have outlined communication technologies e.g. tactile internet, flying networks and holographic calls for future networks in 2030. In [24] and [25], future trends and applications enabling 6G technology have been summarized. Blockchain technology, human centric services and key performance indicators of $6 \mathrm{~g}$ are investigated in these studies. $6 \mathrm{G}$ prospect, challenges and key performance indicators are defined. Authors have illustrated the role of OWC [26] in 6G technology. Some recent articles have provided detailed discussions about green 6G network architecture [27], 6G spectrum management [28], security challenges [29], potential solutions [33], machine learning technologies for 6G [30-31] and performance evolution of terahertz [32] communications. Some publications have discussed data center connectivity [34] and practical implementation of multiple access [35] for 6G networks. Network patterns for $6 \mathrm{G}$ are highlighted in some studies [3637]. $6 \mathrm{G}$ based AI applications [38-39] which will unlock the full potential of radio signals are outlined in some studies. Hardware foundation of AI [40] is proposed in an article. Zhao et al. [41] have provided a survey on intelligent reflective surfaces for $6 \mathrm{G}$ networks. These promising materials can enhance the spectral efficiency [42] in 6G networks. In addition, several countries have started research projects to initiate, develop, define and reshape framework of $6 \mathrm{G}$ networks. Table IV summarizes country wise research initiatives in $6 \mathrm{G}$ networks.

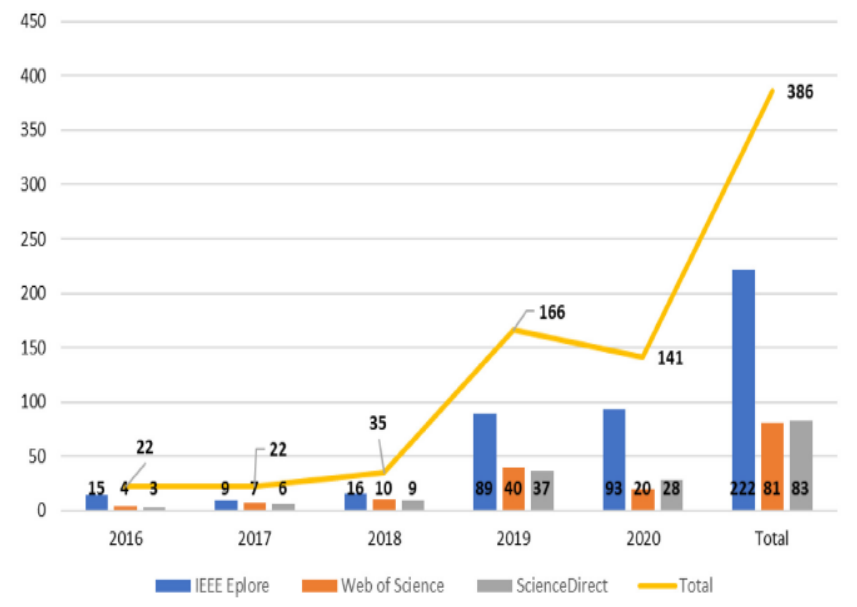

Fig. 3. A Trend of Publications on 6G [21].

TABLE IV. 6G PROJECTS IN DIFFERENT COUNTRIES

\begin{tabular}{|l|l|l|}
\hline Country & Year & Research Initiative \\
\hline 2018 & Finland & 6G initiative was launched in University of Oulu. \\
\hline 2019 & China & $\begin{array}{l}\text { 37 research institutes have started focusing on 6G } \\
\text { research. }\end{array}$ \\
\hline 2019 & USA & $\begin{array}{l}\text { Spectrum between 95 GHz and 3 THz has been } \\
\text { opened. }\end{array}$ \\
\hline 2019 & $\begin{array}{l}\text { South } \\
\text { Korea }\end{array}$ & $\begin{array}{l}\text { KAIST and LE Electronics have established a 6G } \\
\text { research center with collaboration. }\end{array}$ \\
\hline 2020 & Japan & $\begin{array}{l}\text { Sony, Intel and NTT have collaborated to work on 6G } \\
\text { technology. Japan has planned to spend \$US 2 billion } \\
\text { on 6G industrial research. }\end{array}$ \\
\hline 2020 & $\begin{array}{l}\text { Saudi } \\
\text { Arabia }\end{array}$ & $\begin{array}{l}\text { Researchers from KAUST have started working on } \\
\text { 6G technology. }\end{array}$ \\
\hline $2021-$ & $\begin{array}{l}\text { South } \\
\text { Korea }\end{array}$ & $\begin{array}{l}\text { Government of Korea will invest \$169 million to } \\
\text { secure 6G and planning to launch 6G pilot project in } \\
\text { 2026. }\end{array}$ \\
\hline
\end{tabular}




\section{TECHNOLOGY BREAKDOWN}

We have discussed each generation in the aspects of frequency, spatial and time domains as given below. Technology breakdown from $1 \mathrm{G}$ to $6 \mathrm{G}$ is also displayed in Fig. 4.

\section{A. Spatial - 10 Times}

The purview of the Space-Air-Ground integrated network enfolds an extensive range of terminals, satellite communications, flying drones, which proffers two times cost reduction with low number of base stations. Ultra-scale MIMO can improve $50 \%$ throughput without extra costs; thereby 1.5 times cost reduction can be achieved. Intelligent adaptation of beam eventually brings three to four times reduction, while 10 times reduction is possible through different network architectures.

\section{B. Frequency - 10 Times}

In frequency domain, the cost reduction is dependent on utilization of low cost spectrum. Although mmWave, VLC and $\mathrm{THz}$ are capable to offer significant bandwidth for wireless transfer, the befitting scenario is indoor users with pedestrian mobility, which is $70 \%$ of the overall traffics. Thus, higher frequency bands can facilitate with 3 times reduction. Moreover, another 3-4 times reduction is possible by flexible usage of multiple frequency bands.

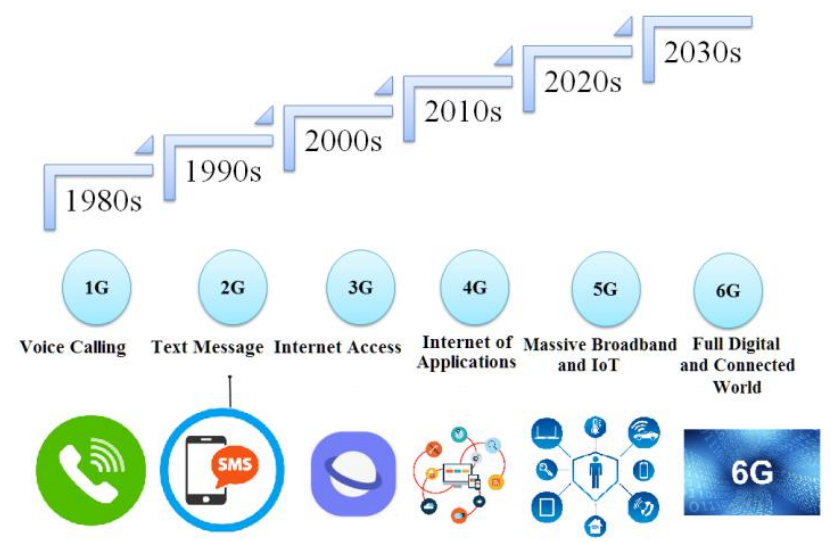

Fig. 4. An Overview of $1 \mathrm{G}-6 \mathrm{G}$ Devices nd the Corresponding Technology Breakdown.

\section{Time - 10 Times}

Another prominent alternative is to profoundly impact the resolution of time-frequency resource to feature flexible frame structure and integrate modulation scheme like index modulation. A fast mode adaptation can enhance the performance with a massive combination of duplex schemes, modulation techniques and frame structures. By incorporating several techniques, we expect 1000 times reduction can be achieved. The core element is AI-assisted intelligent communication which can reduce cost up to 20-50 times.

\section{6G REQUIRES A NEW PARADIGM}

Next generation $6 \mathrm{G}$ network requires wide bandwidth for high resolution and high carrier frequencies for small antennas. A potential issue is to analyze and process radio systems over wide bandwidth without prior information of signal, modulation and carrier frequency. An idea option is photonics defined system as it can provide high spectrum capacity with extreme bandwidth. It is an extended version of microwave photonics through coherent optics, optical computing and photonics DSP. A paradigm shift and hyper-S curve [43] presenting a revolution of mobile of communication technologies is shown in Fig. 5.

Open loop control, reduced feedbacks, software defined systems and interference cancellation have developed this system. A radical innovation is expected in case of $6 \mathrm{G}$ which will result into a new $\mathrm{S}$ curve. The logical start of $6 \mathrm{G}$ is shown in Fig. 6.

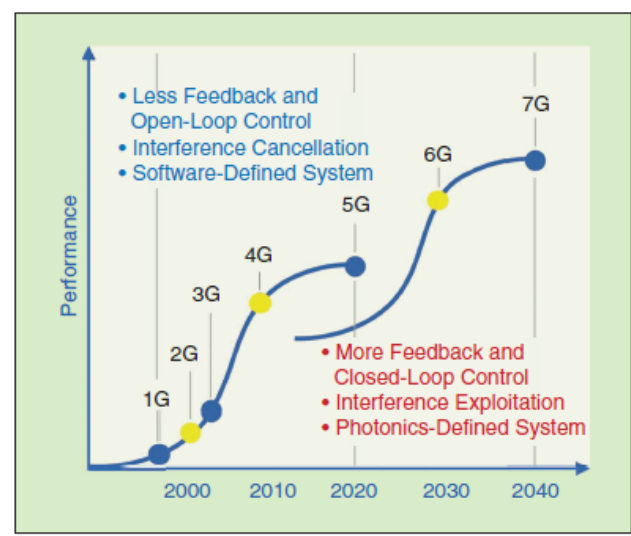

Fig. 5. Hyper-S Curve and Paradigm Shift [43].

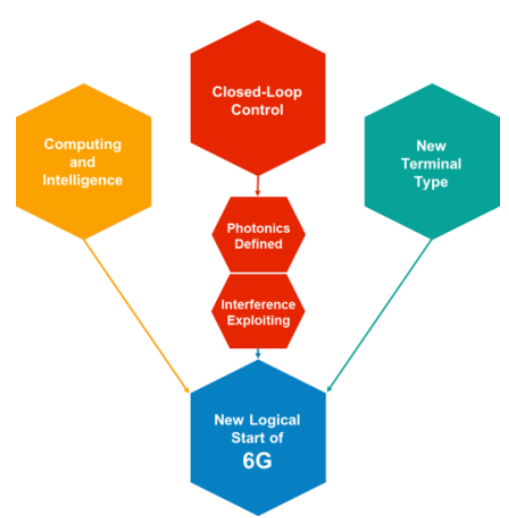

Fig. 6. New Logical Start of 6G.

\section{KEY AREAS IN 6G NETWORKS}

We will discuss key areas in $6 \mathrm{G}$ networks and we have also investigated privacy and security issues in these areas.

\section{A. Real-Time Intelligent Edge}

It is not fully possible to implement Unmanned Aerial Vehicle (UAV) networks with existing technologies as it needs real time intelligence and extremely low latency to control the network. Although 5G technology has supported autonomous driving, however prediction, self-adaption and self-awareness for network entities is not supported [44]. Thus, a new technology is required to overcome these issues. It will be possible through $6 \mathrm{G}$ technology to enable AI-powered services. As AI will be incorporated in vehicle networks, it will support several security mechanisms. However, it will cause new privacy and security issues. Tang et al. [45] 
investigated that both network and physical environments should be considered for a vehicle network as it can reduce malicious activities.

\section{B. Distributed AI}

$6 \mathrm{G}$ networks will support Internet of Everything (IoE). It will make $6 \mathrm{G}$ network advance enough to take intelligent decisions [27]. In addition, IoT needs to support various requirements. 1) The edge device must compute and store data. 2) It should have the capability to clean and abstract data [46]. This approach can improve the privacy and security of the network. Machine learning algorithms can be integrated with $6 \mathrm{G}$ to ensure security [47] and data integrity.

\section{C. $3 D$ Intercoms}

In 6G network, network optimization and designing will move from 2D to 3D [48]. 6G technologies will be capable of supporting 3D communication to enable undersea, UAVs and satellite communication. A 3D intercom can facilitate this feature with accurate time and location. In addition, resource management, routing and mobility characteristics also require network optimization in 3D intercom. Currently, THz bands are being experienced. With this band, some new technologies e.g. quantum and molecular communications can be applied for remote communication [49]. Wei et al. [50] highlighted some security risks for authentication process. In addition, performance of $6 \mathrm{G}$ networks in undersea environment is still unpredicted. Once $6 \mathrm{G}$ network operations in undersea environment are possible, more opportunities and challenges will emerge in near future. Fig. 7 illustrates some application scenarios supported by $6 \mathrm{G}$ technologies.

\section{Intelligent Radio}

The transceiver devices can be separated in 6G while they were designed together in earlier generations. Hence, it has the capability to update itself. Some operating systems are developed on the basis of hardware information and AI technology. Researchers have investigated signal jamming and suspicious activities in data transmission. Thus, $6 \mathrm{G}$ will enable intelligent and secure data transmission.

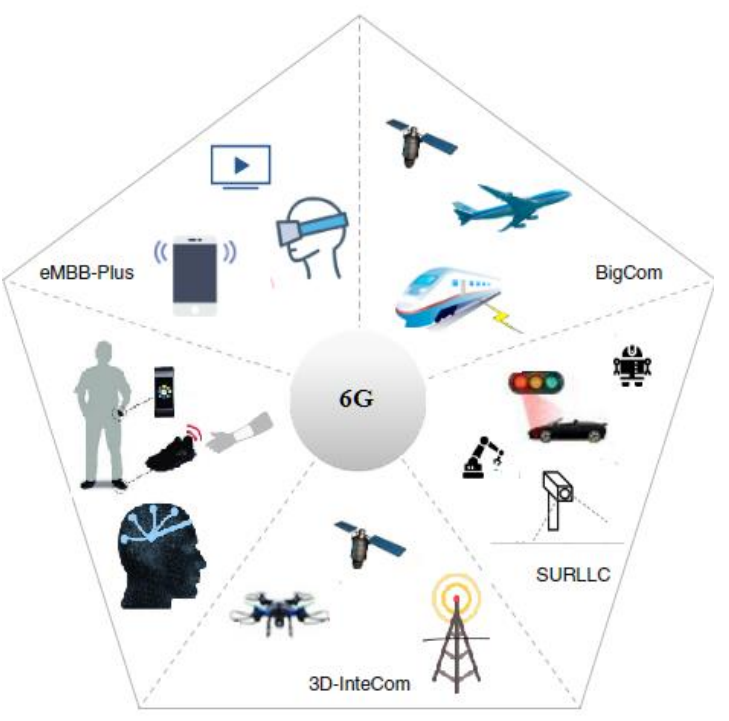

Fig. 7. Applications Supported by $6 \mathrm{G}$.

\section{VII.6G TECHNOLOGIES}

In this section, we have discussed $6 \mathrm{G}$ technologies and associated privacy and security concerns. Table $\mathrm{V}$ presents an overview of $6 \mathrm{G}$ technologies and security issues. While Fig. 8 illustrates potential key technologies of $6 \mathrm{G}$ networks.

TABLE V. EVOLUTION FROM 5G TO 6G

\begin{tabular}{|l|l|l|}
\hline Technology & Reference & Privacy and security issue \\
\hline AI & {$[48]$} & Malicious attack \\
\hline AI & {$[51]$} & Communication \\
\hline $\begin{array}{l}\text { AI and quantum } \\
\text { communication }\end{array}$ & {$[52]$} & Encryption \\
\hline Blockchain & {$[53]$} & Communication \\
\hline Blockchain & {$[54]$} & Access control \\
\hline Blockchain & {$[55]$} & Authentication \\
\hline VLC & {$[56]$} & Malicious attack \\
\hline VLC & {$[57]$} & Communication \\
\hline THz & {$[58]$} & Malicious attack \\
\hline THz & {$[59]$} & Authentication \\
\hline $\begin{array}{l}\text { Quantum } \\
\text { communication }\end{array}$ & {$[60]$} & Encryption \\
\hline
\end{tabular}

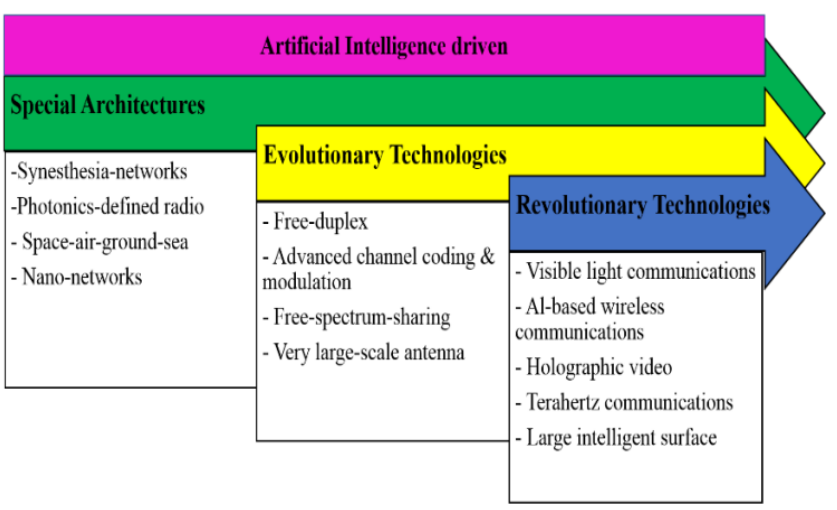

Fig. 8. Key Technologies of 6 G Network.

\section{A. AI}

AI plays the most important role in future network infrastructures as compared to other technologies. AI has gained a lot of attention from various research groups. With this growing research, various privacy and security problems are also emerging. Although $\mathrm{AI}$ is also integrated in $5 \mathrm{G}$ technology, however it is considered as the key component of future $6 \mathrm{G}$. AI technologies are subdivided into physical layer consisting of network infrastructure, architecture layer, computing layer which contains software defined networks, edge/cloud computing and network function virtualization.

\section{B. Quantum Communication}

Another promising technology in $6 \mathrm{G}$ network is quantum communication. It can significantly increase reliability and security of data transmission. Quantum state is affected with any adverse eavesdrop. Quantum communication offers security with essential breakthroughs. It can provide solutions and elevate communication which is not possible to achieve 
through traditional communication techniques [61]. However, it is not the only panacea for all security threats. Although research has been carried out to develop quantum cryptography, but fiber attenuation is a serve issue in long distance quantum communication. Zhang et al. [62] and Nawaz et al. [52] have presented quantum mechanism for secure communication through quantum key distribution models.

\section{Blockchain}

Another prominent technology is 6G network is blockchain. It has several used such as spectrum sharing, distributed ledger technology and network decentralization. S. Dang et al. [48] used network decentralization to enhance network performance. Strinati et al. [63] also increased authentication security through distributed ledger technology. Blockchain technology can also overcome spectrum monopoly and low spectrum utilization [64]. Blockchain privacy concerns are related to communication, authentication and access control. X. Ling et al. [65] have illustrated authentication and secure network access features through blockchain technology.

\section{Visible Light Communication (VLC)}

VLC is a promising technology to meet the rapidly growing needs of wireless connectivity [66]. VLC has been deployed in vehicular Ad Hoc networks and indoor positioning systems. J. Luo et al. [67] have presented an indoor positioning system based on VLC. It is noticed that VLC limits EM interference. Some research studies have demonstrated high speed data transmission by using LEDs. Some deficiencies exist which affect the performance of VLC communication. In particular, VLC technology mainly supports indoor scenario as it is severely affected by natural light. The security issues of VLC technology include communication problem and malicious activities. A SecVLC protocol [57] is developed for secure data transmission in a vehicular network. Fig. 9 presents an overview of $\mathrm{OWC}$ in $6 \mathrm{G}$ technologies. We have provided a detailed discussion of $\mathrm{OWC}$ and $6 \mathrm{G}$ our recent systematic study [68]. 6G is expected revolution in UWPT [69] and UWOC.

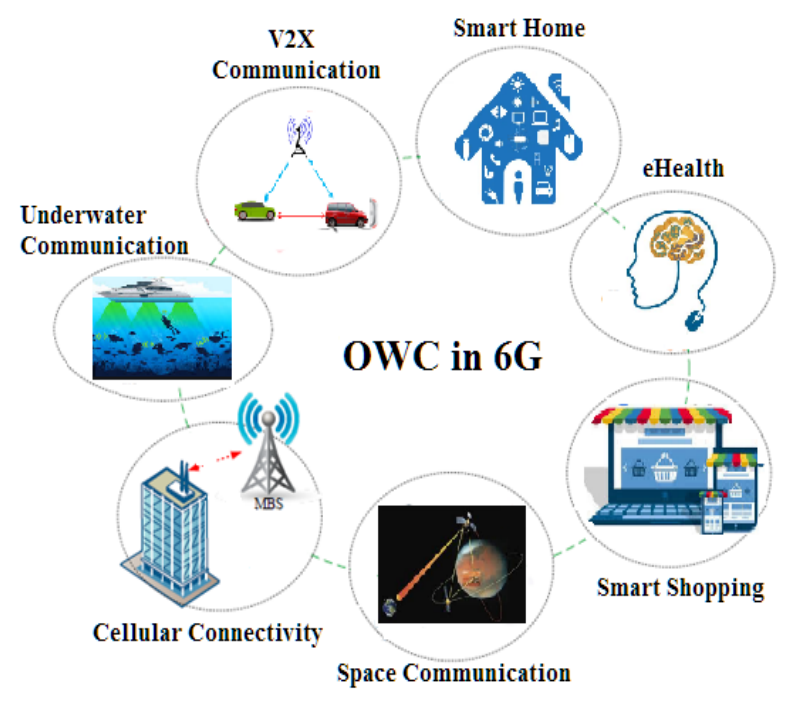

Fig. 9. OWC and 6G.

\section{E. Terahertz Technology $(\mathrm{THz})$}

Existing RF band cannot be utilized for future $6 \mathrm{G}$ technologies [70]. It has spurred the demand for $\mathrm{THz}$ technology. THz communication technology used $0.1-10 \mathrm{THz}$ band. Moreover, it exploits optical signals and EM waves. Huang et al. [27] have highlighted several benefits of $\mathrm{THz}$ band including 100 Gbps data rate, high security and limited eavesdropping. $\mathrm{THz}$ can significantly minimize intercell impact [64]. Strianti et al. [63] have investigated energy consumption problem in $\mathrm{THz}$ communication. $\mathrm{THz}$ faces security risks of authentication and malicious attack. We have summarized a comparison between VLC and $\mathrm{THz}$ communication in Table VI.

TABLE VI. COMPARISON BETWEEN VLC AND THZ

\begin{tabular}{|l|l|l|}
\hline Feature & VLC & $\mathbf{T H z}$ \\
\hline Cost & Cheap & Expensive \\
\hline Data rate & $10 \mathrm{Gbps}$ & $100 \mathrm{Gbps}$ \\
\hline EM radiation & no & yes \\
\hline Transmission & LOS & NLOS \\
\hline Transmission power & Low & High \\
\hline Spectrum regulation & Unlicensed & Liscensed \\
\hline Inter cell interference & No & Yes \\
\hline Bandwidth & $10-100 \mathrm{GHz}$ & $100 \mathrm{THz}$ \\
\hline
\end{tabular}

\section{Potential ChallengeS}

There are several critical challenges which can affect future $6 \mathrm{G}$ technology. In this section, we have discussed big data, power, latency and hardware design challenges.

\section{A. Wireless Big Data}

AI technology has proven its great stature in computer vision tasks. It has potential application in ImageNet big data sets. Such supervised learning method can solve complex optimization challenges in wireless communication. However, there exist many serious concerns for developing public wireless data sets for research purpose. As big data is processed and stored through cloud computing. The DIoE will cause new challenges to manage this data.

\section{B. Portable and Low-Latency Algorithm}

The current AI technologies are developed to meet certain requirements; however, it has limited migration capability. However, an important performance metric is to design portable and low latency algorithms. In addition, latency tradeoff and accuracy is highly required as compared to than traditional computer vision tasks.

\section{Hardware Co-Design}

High density parallel computing methods are required in AI-assisted technologies. Wireless network architecture requires certain parameters to support AI-assisted communication. Moreover, computer performance can face degradation in case of advance materials e.g. graphene transistors and high temperature superconductors. 


\section{Power Supply}

6G technology can make an efficient connection between mobile devices. Energy-efficient algorithms and strategies must be adopted in such cases. 6G will introduce new power control mechanism such as advance wireless power transfer (WPT) for smart devices. It will enable energy harvesting and optimization technique for efficient performance in harsh environment such as undersea environment.

\section{E. Network Security Issue}

Researchers need to focus on privacy concerns in future $6 \mathrm{G}$ technology. They must investigate new security approaches for secure data transmission. A significant extension in $5 \mathrm{G}$ security methods can also enable 6G security. Researchers can find new techniques to efficiently integrate $\mathrm{THz}$ with mmWaves. It can put profound impact on $6 \mathrm{G}$ privacy and security mechanism.

\section{6G POTENTIAL APPLICATIONS}

Every new epoch of network technology introduces new services. In this section, we have outlined some potential applications for future $6 \mathrm{G}$ technology.

\section{A. Multi-Sensory XR Applications}

The low latency and high bandwidth of 5G technology has extended the VR/AR experience for $5 \mathrm{G}$ users. Nonetheless, some existing challenges should be removed in $6 \mathrm{G}$ network. The VR/AR experience will be enhanced in $6 \mathrm{G}$ network. Multiple sensors can be allocated to gather sensory data. Hence, the XR in 6G network will be formulated from URLLC and eMBB. The security concerns of eMBB and URLLC include internal communication, access control and malicious attack. Chen et al. [71] have investigated security problems in URLLC applications. J.M. Hamamreh et al. [72] have suggested a technique to improve security again URLLC attacks. Similarly, Yamakami et al. [73] have proposed a 3D model for secrecy risks in XR applications.

\section{B. Connected Robotics and Autonomous Systems}

Another promising application of $6 \mathrm{G}$ technology is the connected robotics and autonomous systems. A comprehensive autonomous system is required in $6 \mathrm{G}$ network as compared to 5G. This system should be based on a multi-dimensional network. In addition, the system must be capable to embed AI across the network. This feature will support automatic controlling of internal components. Strianti et al. [63] have envisioned resource control, caching and automatic handling in network. They developed an automated factory which contains cloud services, database and UAV networks to make it a complete autonomous system. 6G will be helpful for underwater robotic tasks such as security, imaging and rescue. 6G will enable efficient surveillance, navigation and robotic communication. It will develop a reliable, secure and smooth communication channel for real-time applications. Low latency and high speed data transmission of $6 \mathrm{G}$ will be helpful to obtain video data.

\section{Wireless Brain-Computer Interactions}

The concept of wireless BCI is to develop a link between device and human brain. This device can be placed inside or outside the body. The key application of wireless BCI is to control auxiliary equipment for disabled people. It is expected that BCI will have more applications with involving $6 \mathrm{G}$ technology. In 2015, Chen et al. [74] developed a braincomputer interface to speed up spelling. The security risks of wireless BCI contain encryption and malicious behavior. Several research studies [75-76] have discussed security issues, protection techniques and hacking applications to mitigate security issues.

\section{Accurate Indoor Positioning}

With evolving GPS, outdoor positioning systems have been developed accurately. However, indoor position systems need research attention to cope up with complicated indoor EM propagation. New aspects of full-fledge applications are expected with reliable and accurate indoor positioning services. However, alone RF communication cannot achieve accurate indoor positioning. Such crucial application can only be realized with $6 \mathrm{G}$ technology.

\section{E. Holographic Communications}

6G will make it possible to realize virtual in-person meeting than traditional video conferencing. It can be achieved through a realistic projection of real time mobility in short time. It is not sufficient to transmit 3D image with voice to realize in-person presence. However, it requires a stereo audio incorporated in 3D video. We can state that user interacts with holographic data and can carry out possible modifications as needed. This scenario can be captured by reliable communication networks with extremely large bandwidth.

\section{F. Tactile Communications}

After realizing holographic communication for virtual inperson meeting, it is advantageous to carry out tactile communication to transfer the physical interaction remotely. Specifically, it includes interpersonal communication, cooperative automated driving and teleoperation. Stringent demands or these applications can be met through reliable cross-layer communication-system. Moreover, delay can be mitigated by carefully handling handover, scheduling, queuing and buffering.

\section{G. Internet of Nano-Things}

Nanotechnology is providing remarkable opportunities to design advance materials. It has developed nanodevices like nanosensors. It has the capability to perform simple task and enable internet connectivity. IoNT [77] is developed by integrating nanotechnology with IoT. It has the ability to sense and transmit information. IoNT can be deployed with allied technologies such as big data, cloud computing, WSN, UWSN [78-79] and IoT. However, IoNT faces limited memory space issue for real-time implementation as data storage depends on the size of nano memory. Another potential issue is high biological noise and congestion control in nanodevices. An overview of $6 \mathrm{G}$ applications is summarized in figure 10 .

\section{H. Intelligent Internet of Medical Things (IIoMT)}

IIoMT will remove space and time hurdles to perform surgical operations. $6 \mathrm{G}$ will provide high speed communication for efficient performance of telesurgery beyond boundaries. IIoMT will make use of holographic communication, tactile communication and AR/VR to assist remote doctors. Thus, $6 \mathrm{G}$ 
technology will ensure intelligent healthcare. It is expected to bring mobile hospital technology which can remove ambulance services. In future, it can offer medical devices to perform special medical tasks which can greatly reduce the possibility of medical staff in contacting with viruses. An overview of $6 \mathrm{G}$ applications is summarized in Fig. 10.

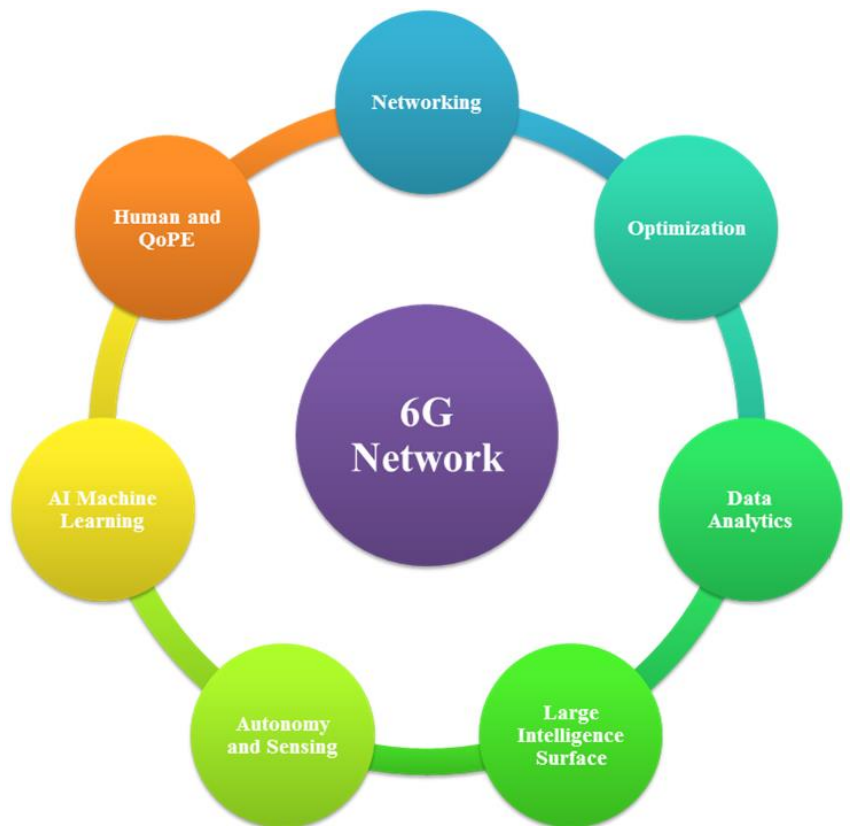

Fig. 10. Potential Applications of 6G.

\section{Conclusions}

During the worldwide deployment of $5 \mathrm{G}$, academia and industrial experts have started conceptualizing 6G. Unlike 5G networks, the next generation $6 \mathrm{G}$ will focus on communication among users, industries and multiple objects. Network transmission performance is no longer only important parameter; blockchain technology, IoT and AI have become important components. $6 \mathrm{G}$ network will keep penetrating into virtual society, human-perceived actions and ubiquitous spaces. It will provide a secure, reliable, intelligent, deep, seamless and holographic network infrastructure. 6G network will fulfil the growing demands of industries with continuous innovations of AI. We outlined research activities in different countries which aim to create a vision of $6 \mathrm{G}$. $6 \mathrm{G}$ will enable many new technologies such as VLC, tactile and holographic communication. In conclusion, we expect that this review article will pave the way to identify $6 \mathrm{G}$ roadmap. This paper reviews the key technologies and areas of $6 \mathrm{G}$ networks and highlights a prospective on future research. We have presented a vision of $6 \mathrm{G}$ network as a research guide for readers. We have also addressed key features, security challenges and explained potential applications which will be supported in 6G. We have presented an overview of $1 \mathrm{G}$ to $6 \mathrm{G}$. We then examine the key areas of $6 \mathrm{G}$ network. This review article started by highlighting the historical overview of communication technologies and their pivotal elements aiming at fostering future $6 \mathrm{G}$ in various dimensions. Then, we discussed technology breakdown, potential challenges associated with future $6 \mathrm{G}$ technology and possible solutions to foster $6 \mathrm{G}$. In addition, we have profoundly examined research activities in different countries including industries and research institutes. Finally, this study concludes with potential applications of future 6G. The key contribution of our study is that it clarifies the promising solution for potential issues and challenges in $6 \mathrm{G}$ technology. Thus, this review will open new horizons for future research directions.

\section{REFERENCES}

[1] P. Yang, Y. Xiao, M. Xiao, S. Li, 6g wireless communications: vision and potential techniques, IEEE Network 33 (4) (2019) 70-75.

[2] K.B. Letaief, W. Chen, Y. Shi, J. Zhang, Y.-J.A. Zhang, The roadmap to 6g: Ai empowered wireless networks, IEEE Commun. Mag. 57 (8) (2019) 84-90.

[3] T. Zhu, P. Xiong, G. Li, W. Zhou, S. Y. Philip, Differentially private model publishing in cyber physical systems, Future Generat. Comput. Syst..

[4] K. David and H. Berndt, "6G vision and requirements: Is there any need for beyond 5G?” IEEE Veh. Technol. Mag., vol. 13, no. 3, pp. 72-80, Sep. 2018.

[5] T. Chen, S. Barbarossa, X. Wang, G. B. Giannakis, and Z.-L. Zhang, "Learning and management for internet of things: Accounting for adaptivity and scalability," Proc. IEEE, vol. 107, no. 4, pp. 778-796, Apr. 2019.

[6] W. Saad, M. Bennis, and M. Chen, "A vision of $6 \mathrm{G}$ wireless systems: Applications, trends, technologies, and open research problems," IEEE Netw., to be published, doi: 10.1109/MNET.001.1900287.

[7] K. Wakunami et al., "Projection-type see-through holographic threedimensional display," Nature Commun., vol. 7, no. 1, pp. 1-7, Oct. 2016.

[8] E. Ahmed, I. Yaqoob, A. Gani, M. Imran, and M. Guizani, "Internetofthings- based smart environments: State of the art, taxonomy, and open research challenges," IEEE Wireless Commun., vol. 23, no. 5, pp. $10-16$, Oct. 2016.

[9] N. Zhang, S. Zhang, P. Yang, O. Alhussein, W. Zhuang, and X. Shen, "Software defined space-air-ground integrated vehicular networks: Challenges and solutions," IEEE Commun. Mag., vol. 55, no. 7, pp. 101-109, Jul. 2017.

[10] S. Zhang, S. Xu, G. Y. Li, and E. Ayanoglu, "First 20 years of green radios," IEEE Trans. Green Commun. Netw., vol. 4, no. 1, pp. 1-15, Mar. 2020.

[11] P. Yang, Y. Xiao, M. Xiao, and S. Li, "6G wireless communications: Vision and potential techniques," IEEE Netw., vol. 33, no. 4, pp. 70-75, Jul. 2019.

[12] K. B. Letaief, W. Chen, Y. Shi, J. Zhang, and Y.-J. A. Zhang, "The roadmap to $6 \mathrm{G}$ : AI empowered wireless networks," IEEE Commun. Mag., vol. 57, no. 8, pp. 84-90, Aug. 2019.

[13] China Mobile Limited, "China mobile limited (2015) annual report 2015," China Mobile Limited, Tech. Rep., 2016. [Online]. Available: http://www.chinamobileltd.com/en/ir/reports/ar2015.pdf

[14] X. Gong and C. Cortese, "A socialist market economy with Chinese characteristics: The accounting annual report of China Mobile," Accounting Forum, vol. 41, no. 3, pp. 206-220, 2017.

[15] TTH Council Asia-Pacific, "APAC FTTH market panorama report 2019," FTTH Council Asia-Pacific, Tech. Rep., 2019. [Online]. Available: http://www.fthcouncilap.org/wpcontent/uploads/2019/04/FTTH-APAC-Panorama-Report2019_Low.pdf

[16] Dang, Shuping, et al. "What should 6G be?." Nature Electronics 3.1 (2020): 20-29.

[17] Huang, Tongyi, et al. "A survey on green 6G network: Architecture and technologies." IEEE Access 7 (2019): 175758-175768.

[18] Raghavan, V. \& Li, J. Evolution of physical-layer communications research in the post-5G era. IEEE Access 7, 10392-10401 (2019).

[19] Calvanese Strinati, E. et al. 6G: the next frontier: from holographic messaging to artificial intelligence using subterahertz and visible light communication. IEEE Veh. Technol. Mag. 14, 42-50 (2019). 
[20] Saad, W., Bennis, M. \& Chen, M. A vision of 6G wireless systems: applications, trends, technologies, and open research problems. IEEE Netw. https://doi.org/10.1109/MNET.001.1900287 (2019).

[21] Lu, Yang, and Xianrong Zheng. "6G: A survey on technologies, scenarios, challenges, and the related issues." Journal of Industrial Information Integration (2020): 100158.

[22] E. Basar, Reconfigurable intelligent surface-based index modulation: a new beyond MIMO paradigm for 6G, IEEE Trans. Commun. 68 (5) (2020) 3187-3196.

[23] S.M. Bohloul, Smart cities: a survey on new developments, trends, and opportunities, J. Ind. Integr. Manag. (2020) Early Access.

[24] E. Carter, P. Adam, D. Tsakis, S. Shaw, R. Watson, P. Ryan, Enhancing pedestrian mobility in Smart Cities using Big Data, J. Manag. Anal. (2020) 1-16.

[25] S. Chen, S. Sun, G. Xu, X. Su, Y. Cai, Beam-space multiplexing: practice, theory, and trends, from $4 \mathrm{G}$ TD-LTE, $5 \mathrm{G}$, to $6 \mathrm{G}$ and Beyond, IEEE Wirel. Commun. 27 (2) (2020) 162-172.

[26] M.Z. Chowdhury, M. Shahjalal, M. Hasan, Y.M. Jang, The role of optical wireless communication technologies in $5 \mathrm{G} / 6 \mathrm{G}$ and IoT solutions: prospects, directions, and challenges, Appl. Sci. 9 (20) (2019) 4367.

[27] T. Huang, W. Yang, J. Wu, J. Ma, X. Zhang, D. Zhang, A survey on green 6G network: architecture and technologies, IEEE Access 7 (2019) 175758-175768.

[28] M. Matinmikko-Blue, S. Yrjölä, P. Ahokangas, Spectrum management in the 6G Era: the role of regulation and spectrum sharing, 2020 2nd Wireless Summit (6G SUMMIT), IEEE, 2020, March, pp. 1-5.

[29] G. Gui, M. Liu, F. Tang, N. Kato, F. Adachi, 6G: opening new horizons for integration of comfort, security and intelligence, IEEE Wireless Commun (2020).

[30] N. Kato, B. Mao, F. Tang, Y. Kawamoto, J. Liu, Ten challenges in advancing machine learning technologies toward 6G, IEEE Wireless Commun. (2020).

[31] S.J. Nawaz, et al., Quantum machine learning for 6G communication networks: state-of-the-art and vision for the future, IEEE Access 7 (2019) 46317-46350.

[32] L. Yan, C. Han, J. Yuan, Hybrid precoding for $6 \mathrm{G}$ terahertz communications: performance evaluation and open problems, 2020 2nd 6G Wireless Summit (6G SUMMIT), IEEE, 2020, pp. 1-5.

[33] Alsharif, Mohammed H., et al. "Sixth Generation (6G) Wireless Networks: Vision, Research Activities, Challenges and Potential Solutions." Symmetry 12.4 (2020): 676.

[34] Rommel, S., Raddo, T. R. \& Monroy, I. T. Data center connectivity by $6 \mathrm{G}$ wireless systems. In Proc. IEEE PSC https://doi.org/10.1109/PS.2018.8751363 (IEEE, 2018).

[35] Clazzer, F. et al. From 5G to 6G: has the time for modern random access come? Preprint at https://arxiv.org/abs/1903.03063 (2019).

[36] Yaacoub, E. \& Alouini, M.-S. A key 6G challenge and opportunityconnecting the remaining 4 billions: a survey on rural connectivity. Preprint at https://arxiv.org/abs/1906.11541 (2019).

[37] Giordani, M., Polese, M., Mezzavilla, M., Rangan, S. \& Zorzi, M. Towards 6G networks: use cases and technologies. Preprint at https://arxiv.org/abs/1903.12216 (2019).

[38] Stoica, R.-A. \& de Abreu, G. T. F. 6G: the wireless communications network for collaborative and AI applications. Preprint at https://arxiv.org/abs/1904.03413 (2019).

[39] Letaief, K. B., Chen, W., Shi, Y., Zhang, J. \& Zhang, Y. A. The roadmap to 6G: AI empowered wireless networks. IEEE Commun. Mag. 57, 84-90 (2019).

[40] Renzo, D. et al. Smart radio environments empowered by reconfigurable AI meta-surfaces: an idea whose time has come. EURASIP J. Wireless Commun. Netw. 2019, 129 (2019).

[41] Zhao, J. A Survey of intelligent reflecting surfaces (IRSs): towards 6G wireless communication networks. Preprint at https://arxiv.org/abs/1907.04789v3 (2019).
[42] Basar, E. Reconfigurable intelligent surface-based index modulation: a new beyond MIMO paradigm for $6 \mathrm{G}$. Preprint at https://arxiv.org/abs/1904.06704v2 (2019).

[43] Zong, Baiqing, et al. "6G technologies: Key drivers, core requirements, system architectures, and enabling technologies." IEEE Vehicular Technology Magazine 14.3 (2019): 18-27.

[44] M.G. Kibria, K. Nguyen, G.P. Villardi, O. Zhao, K. Ishizu, F. Kojima, Big data analytics, machine learning, and artificial intelligence in nextgeneration wireless networks, IEEE Access 6 (2018) 32328-32338.

[45] F. Tang, Y. Kawamoto, N. Kato, J. Liu, Future intelligent and secure vehicular network toward 6g: machine-learning approaches, Proc. IEEE.

[46] I. Tomkos, D. Klonidis, E. Pikasis, S. Theodoridis, Toward the $6 \mathrm{~g}$ network era: opportunities and challenges, IT Prof. 22 (1) (2020) 34-38.

[47] L. Loven, T. Lepp_anen, E. Peltonen, J. Partala, E. Harjula, P. Porambage, M. Ylianttila, J. Riekki, Edge Ai: A Vision for Distributed, Edge-Native Artificial Intelligence in Future 6g Networks, The 1st 6G Wireless Summit, 2019, pp. 1-2.

[48] S. Dang, O. Amin, B. Shihada, M.-S. Alouini, What should 6g be? Nat. Electron. 3 (1) (2020) 20-29.

[49] M. Katz, P. Pirinen, H. Posti, Towards 6g: getting ready for the next decade, in: 2019 16th International Symposium on Wireless Communication Systems (ISWCS), IEEE, 2019, pp. 714-718.

[50] Y. Wei, H. Liu, J. Ma, Y. Zhao, H. Lu, G. He, Global voice chat over short message service of beidou navigation system, in: 2019 14th IEEE Conference on Industrial Electronics and Applications (ICIEA), IEEE, 2019, pp. 1994-1997.

[51] T. Hong, C. Liu, M. Kadoch, Machine learning based antenna design for physical layer security in ambient backscatter communications, Wireless Commun. Mobile Comput. (2019).

[52] S.J. Nawaz, S.K. Sharma, S. Wyne, M.N. Patwary, M. Asaduzzaman, Quantum machine learning for $6 \mathrm{~g}$ communication networks: state-ofthe-art and vision for the fu-ture, IEEE Access 7 (2019) 46317-46350.

[53] P. Ferraro, C. King, R. Shorten, Distributed ledger technology for smart cities, the sharing economy, and social compliance, IEEE Access 6 (2018) 62728-62746.

[54] K. Kotobi, S.G. Bilen, Secure blockchains for dynamic spectrum access: a decentralized database in moving cognitive radio networks enhances security and user access, IEEE Veh. Technol. Mag. 13 (1) (2018) 32-39.

[55] S. Kiyomoto, A. Basu, M.S. Rahman, S. Ruj, On blockchain-based authorization architecture for beyond-5g mobile services, in: 2017 12th International Conference for Internet Technology and Secured Transactions (ICITST), IEEE, 2017, pp. 136-141.

[56] S. Cho, G. Chen, J.P. Coon, Enhancement of physical layer security with simultaneous beamforming and jamming for visible light communication systems, IEEE Trans. Inf. Forensics Secur. 14 (10) (2019) 2633-2648.

[57] S. Ucar, S. Coleri Ergen, O. Ozkasap, D. Tsonev, H. Burchardt, Secvlc: secure visible light communication for military vehicular networks, in: Proceedings of the 14th ACM International Symposium on Mobility Management and Wireless Access, 2016, pp. 123-129.

[58] J. Ma, R. Shrestha, J. Adelberg, C.-Y. Yeh, Z. Hossain, E. Knightly, J.M. Jornet, D.M. Mittleman, Security and eavesdropping in terahertz wireless links, Nature 563 (7729) (2018) 89-93.

[59] I.F. Akyildiz, J.M. Jornet, C. Han, Terahertz band: next frontier for wireless communications, Phys. Commun. 12 (2014) 16-32.

[60] J.-Y. Hu, B. Yu, M.-Y. Jing, L.-T. Xiao, S.-T. Jia, G.-Q. Qin, G.-L. Long, Experimental quantum secure direct communication with single photons, Light Sci. Appl. 5 (9) (2016), e16144.

[61] L. Gyongyosi, S. Imre, H.V. Nguyen, A survey on quantum channel capacities, IEEE Commun. Surv. Tutorials 20 (2) (2018) 1149-1205.

[62] W. Zhang, D.-S. Ding, Y.-B. Sheng, L. Zhou, B.-S. Shi, G.-C. Guo, Quantum secure direct communication with quantum memory, Phys. Rev. Lett. 118 (22) (2017), 220501.

[63] E. C. Strinati, S. Barbarossa, J. L. Gonzalez-Jimenez, D. Ktenas, N. Cassiau, C. Dehos, 6g: the Next Frontier, arXiv_Preprint arXiv:1901.03239. 
[64] Z. Zhang, Y. Xiao, Z. Ma, M. Xiao, Z. Ding, X. Lei, G.K. Karagiannidis, P. Fan, $6 \mathrm{~g}$ wireless networks: vision, requirements, architecture, and key technologies, IEEE Veh. Technol. Mag. 14 (3) (2019) 28-41.

[65] X. Ling, J. Wang, T. Bouchoucha, B.C. Levy, Z. Ding, Blockchain radio access network (b-ran): towards decentralized secure radio access paradigm, IEEE Access 7 (2019) 9714-9723.

[66] M.S. Islim, R.X. Ferreira, X. He, E. Xie, S. Videv, S. Viola, S. Watson, N. Bamiedakis, R.V. Penty, I.H. White, et al., Towards $10 \mathrm{gb} / \mathrm{s}$ orthogonal frequency division multiplexingbased visible light communication using a gan violet microled, Photon. Res. 5 (2) (2017) A35-A43.

[67] J. Luo, L. Fan, H. Li, Indoor positioning systems based on visible light communication: state of the art, IEEE Commun. Surv. Tutorials 19 (4) (2017) 2871-2893.

[68] Mehedi, Syed Agha Hassnain Mohsan Md, et al. "A Systematic Review on Practical Considerations, Recent Advances and Research Challenges in Underwater Optical Wireless Communication." (2020): 11-7.

[69] Mohsan, Syed Agha Hassnain, et al. "A Review on Research Challenges, Limitations and Practical Solutions for Underwater Wireless Power Transfer." environment 11.8 (2020).

[70] S. Elmeadawy, R.M. Shubair, $6 \mathrm{~g}$ wireless communications: future technologies and research challenges, in: 2019 International Conference on Electrical and Computing Technologies and Applications (ICECTA), IEEE, 2019, pp. 1-5.
[71] R. Chen, C. Li, S. Yan, R. Malaney, J. Yuan, Physical layer security for ultra-reliable and low-latency communications, IEEE Wireless Commun. 26 (5) (2019) 6-11.

[72] J.M. Hamamreh, E. Basar, H. Arslan, Ofdm-subcarrier index selection for enhancing security and reliability of $5 \mathrm{~g}$ urllc services, IEEE Access 5 (2017) 25863-25875.

[73] Yamakami, A privacy threat model in xr applications, in: International Conference on Emerging Internetworking, Data \& Web Technologies, Springer, 2020, pp. 384-394.

[74] X. Chen, Y. Wang, M. Nakanishi, X. Gao, T.-P. Jung, S. Gao, Highspeed spelling with a noninvasive brain-computer interface, Proc. Natl. Acad. Sci. Unit. States Am. 112 (44) (2015) E6058-E6067.

[75] P. McCullagh, G. Lightbody, J. Zygierewicz, W.G. Kernohan, Ethical challenges associated with the development and deployment of brain computer interface technology, Neuroethics 7 (2) (2014) 109-122.

[76] R.A. Ramadan, A.V. Vasilakos, Brain computer interface: control signals review, Neurocomputing 223 (2017) 26-44.

[77] Pramanik, Pijush Kanti Dutta, et al. "Advancing Modern Healthcare With Nanotechnology, Nanobiosensors, and Internet of Nano Things: Taxonomies, Applications, Architecture, and Challenges." IEEE Access 8 (2020): 65230-65266.

[78] Mohsan, Syed Agha Hassnain, et al. "Investigating Transmission Power Control Strategy for Underwater Wireless Sensor Networks."

[79] Mohsan, Syed Agha Hassnain, et al. "Impact of Circular Field in Underwater Wireless Sensor Networks." 